\title{
Multivariate behavioural response of harlequin ducks to aircraft disturbance in Labrador
}

\author{
R. IAN GOUDIE* \\ Atlantic Cooperative Wildlife Ecology Research Network, Department of Biology, Memorial University of Nemfoundland, \\ St Fohn's, NL, Canada A1B $3 X 9$
}

Date submitted: 6 April 2005 Date accepted: 13 January 2006

\section{SUMMARY}

The effects of low-level aircraft over-flights on behaviour of harlequin ducks (Histrionicus histrionicus) breeding in central Labrador were quantified during 2000-2002. The Canadian Department of National Defence supports a low-level training programme in the $130000 \mathrm{~km}^{2}$ Military Training Area of Labrador involving military jets. The Institute for Environmental Monitoring and Research (IEMR) undertakes scientific research into environmental impacts of low-level military jet over-flights. A suite of 17 behavioural categories of paired male and female harlequin ducks was modelled, and a canonical variable representing alert behaviour, inactivity on the water and decreased inactivity out of water in response to over-flights represented $73.1 \%$ of the variance in the data cluster and provided marked separation of disturbed and undisturbed groups. Behavioural responses of harlequin ducks to military jets were 23 times stronger than their responses to floatplanes, helicopters and military cargo planes, and the significant interaction of aircraft type and noise indicated that noise may be the primary stressor affecting behaviour. A quadratic response of the canonical variable to noise generated from aircraft during standardized 30-minute observation periods was defined. The multivariate analyses were more robust because they indicated covariance in behavioural categories associated with disturbance that was not originally detected in univariate analyses, suggesting the importance of integrating behaviours other than overt responses. The significant effects of military jet over-flights on harlequin duck behaviour emphasize the need to evaluate potential population consequences of aircraft disturbance.

Keymords: behavioural response, canonical variable, covariance, dose-response, jet aircraft noise, multivariate analyses

\section{INTRODUCTION}

Through behaviour, an animal may avoid a disturbance (for example by flying away) or habituate if a stimulus is perceived

*Correspondence: Dr R. Ian Goudie Tel: +1 7097378141 Fax: +1

7097373018 e-mail: igoudie@mun.ca as harmless (Korn \& Moyer 1966). Studies of responses of animals to aircraft have generally involved classifying observed behaviour into categories from non-response to startle (Brown 1990). The behaviour of an animal is affected simultaneously by many biotic (and abiotic) factors, and there is synergism and feedback among different kinds of responses to a stressor. This multiplicity and interaction make it difficult to analyse ecological systems especially in univariate statistical designs. Univariate methods are extremely powerful in situations where the response of a single variable is of sole interest (such as demonstration of dose-response) and other factors can be controlled.

In ecological research, it is more often the case that the question at hand can be answered only by considering a number of variables interacting simultaneously. Hence the emphasis is on sets of variables rather than individual variables (McGarigal et al. 2000). I considered that the noise resulting from aircraft over-flights in Labrador affected many different, but partially correlated aspects of the behaviour of breeding harlequin ducks (Histrionicus histrionicus). These pieces of information need to be combined into a single best description of response through multivariate statistical analyses.

Noise is the primary stressor affecting wildlife during aircraft over-flights (Brown 1990, 2001b; Ward et al. 2001), and adverse outcomes in harlequin ducks increased with corresponding increases in the level of exposure (Goudie \& Jones 2004). Aircraft noise differs with aircraft type, and typically there is a threshold level beyond which response increases markedly (Pater 2001), response varies among species (Ryals et al. 1999), and consequently birds may respond differently to different situations and aircraft types (Grubb \& Bowerman 1997). Fixed wing and rotary blade aircraft types generate high amplitude noise but are anticipatory (i.e. have a gradual onset) in nature compared to noise from military jets, which is very high in amplitude and is sudden in onset (Pigeon 2001).

Goudie and Jones (2004) demonstrated effects of military jet noise on behaviour of harlequin ducks using a Before-AfterControl-Impact study design. In this paper, I focus on refining the understanding of behavioural responses within the 30minute watch period when over-flights occurred at Fig River, Labrador $\left(53^{\circ} 03^{\prime} \mathrm{N}, 63^{\circ} 09^{\prime} \mathrm{W}\right)$. I assess the inter-relationship of behaviours as a collective response to being disturbed by low-flying aircraft. The analyses focus primarily on military jets, but also include low numbers of single (turbo) prop floatplanes and rotary-blade helicopters. I compare these data to the same behaviours without disturbance, because previous 
analyses focused on overt responses using single behaviours (Goudie \& Jones 2004).

Harlequin ducks (Histrionicus histrionicus) are small sea ducks that inhabit fast-moving rivers and streams during the breeding season (Robertson \& Goudie 1999), and their populations are sensitive to relatively small changes in adult survival (Goudie et al. 1994). The eastern North American population of harlequin ducks that breed throughout central Labrador was listed as endangered in 1990, and downlisted to a species of concern in 2001 (URL http://www. sararegistry.gc.ca).

The Canadian Department of National Defence (DND) supports a low-level training programme involving military jets in a Military Training Area (MTA) encompassing about $130000 \mathrm{~km}^{2}$ of central and southern Labrador. Following an environmental impact statement (EIS), management actions by DND are to be adjusted based on scientific research. Military jets frequently follow river valleys during low-level sorties (30-150 $\mathrm{m}$ above ground level) at speeds of 780 $890 \mathrm{~km} \mathrm{~h}^{-1}$, generating loud noise exceeding $100 \mathrm{dBA}$ (DND 1994; Pigeon 2001).

My study addressed the following questions: (1) were there multiple behaviours (covariance) involved in responses to disturbances; (2) were there relationships between behavioural responses and dose of aircraft noise; and (3) were there differences in response related to aircraft type?

\section{METHODS}

\section{Behaviour}

Field personnel observed and quantified behaviour of breeding pairs of harlequin ducks during mid-May to midJune of 2001 and 2002. A focal-individual sampling approach (Altmann 1974) was applied and linked to known individuals, because most harlequin ducks at Fig River $(n=95)$ were individually marked from 1999 to 2002 with field-readable coloured plastic leg bands.

Behaviour of harlequin ducks was characterized during bouts or states (such as feeding and resting; see Martin \& Bateson 1986). For standardized watches, focal birds were monitored for 30 minutes (or until lost from sight) using binoculars and/or $(20 \times-60 \times)$ spotting scopes. Instantaneous behavioural classifications of focal birds were recorded every 15 seconds, using digital watches with countdown-return beeper functions, from a suite of 17 general behavioural categories (Table 1). To minimize the chance that individuals were observed more than once and to maximize the independence of our data, a new individually colour-marked bird was selected for observation, or observers changed location to find new birds after each 30-minute observation period was completed.

Since instantaneous data recorded every 15 seconds were not statistically independent within each 30-minute watch, frequencies of behavioural categories were summed over each
Table 1 General categories used to summarize behaviours of harlequin ducks. Behaviours were segregated into those on the water and those also recorded out of the water (indicated ho) for a total of 17 types.

\begin{tabular}{|c|c|}
\hline Behaviour & Description \\
\hline Agonism (ho) & $\begin{array}{l}\text { Aggressive interactions among harlequin ducks, } \\
\text { including chasing and sometimes fighting } \\
\text { with conspecifics }\end{array}$ \\
\hline Courtship & $\begin{array}{l}\text { All courtship behaviour (on the water), for } \\
\text { example inciting, prone, copulation }\end{array}$ \\
\hline Feed & $\begin{array}{l}\text { All aspects of obtaining food, including dip, } \\
\text { dive, submerged, pause or glean }\end{array}$ \\
\hline Peer & $\begin{array}{l}\text { Looking into water (may be associated with food } \\
\text { seeking) }\end{array}$ \\
\hline Locomotion (ho) & $\begin{array}{l}\text { All types of movements, for example swim, } \\
\text { scoot, fly or walk }\end{array}$ \\
\hline Preen (ho) & $\begin{array}{l}\text { Feather maintenance using the bill as well as } \\
\text { flapping and shaking }\end{array}$ \\
\hline Inactive (ho) & $\begin{array}{l}\text { Inactivity, including possible resting, sleeping } \\
\text { and head down }\end{array}$ \\
\hline Social (ho) & Directed calls and head nods \\
\hline Vigilant (ho) & $\begin{array}{l}\text { Maintaining a look-out (vigil), usually while the } \\
\text { mate feeds or sleeps }\end{array}$ \\
\hline Alert (ho) & $\begin{array}{l}\text { Head stretched upward, body erect/tense, } \\
\text { re-orientation and agitation, often accom- } \\
\text { panied with locomotion. Includes startle } \\
\text { responses such as splash dive and panic flush }\end{array}$ \\
\hline
\end{tabular}

watch; each behavioural watch contributed one data record representing the sums of the frequencies of the each recorded behaviours (Martin \& Bateson 1986). These frequencies were converted to proportions for use in the multivariate analyses. I re-titled the behaviour 'rest', as presented in Goudie and Jones (2004) to 'inactivity', because the lack of observable motile behaviours did not necessarily mean that they were resting per se. Virtually all female harlequin ducks present on the study area were paired, and there were slightly more males than females.

\section{Sound and noise data}

A detailed description of methods used for collecting sound and noise data are presented in Goudie and Jones (2004). In this paper, I use the parameter $\mathrm{L}_{\max }$ which represents the maximum sound pressure level (as A-weighted decibels) measured over the sampled period (Larson Davis Laboratories 1997). For aircraft, this represented the highest $\mathrm{L}_{\text {max }}$ recorded during over-flight events, and for undisturbed situations it represented the highest recorded $\mathrm{L}_{\max }$ during behavioural watches.

\section{Statistical analyses}

I used the general linear model (GLM) approach (SAS Institute Inc. 1999). Because the sample sizes were much 
larger, known individuals were sampled many times over each year. Therefore, I included model terms for the known individuals that were nested within disturbed and undisturbed categories for female and male harlequin ducks. For example the GLM statement to assess effect of aircraft noise and type on behaviour was:

$$
\begin{aligned}
\text { Behaviour }= & \text { Group }(\text { who })+\text { noise }^{2}+\text { aircraft type } \\
& +\left(\text { noise }^{2} \times \text { aircraft type }\right) .
\end{aligned}
$$

This effectively controlled for variance associated with individuals, increased the degrees of freedom in the numerator and reduced the sum of squares in the error term, thereby reducing the potential for a type 1 error.

My statistical models encompassed response variables with categories (undisturbed male and female, disturbed male and female) in relation to the proportion of time spent in the $17 \mathrm{de}-$ fined behavioural categories, and were therefore appropriate for the application of multivariate analysis of variance (MANOVA), which maximizes the ratio of among-group to within-group variance in canonical scores. Subsequent to a statistically significant MANOVA, a discriminant analysis (DA) was applied. It is logical to consider DA as an extension of MANOVA, because overall I was interested in testing the null hypothesis that the groups did not differ. Once differences were detected I used DA to describe the linear combinations of dependent variables that maximally discriminate among groups. In other words, MANOVA and DA corresponded to the inferential and descriptive aspects of analyses in much the same way as univariate ANOVA and subsequent multiple range tests do, because the last seek to describe where the differences among groups lie (McGarigal et al. 2000).

Significance of the MANOVA was assessed based on Wilks' lambda, the likelihood ratio statistic that tests the null hypothesis that the group means are equal in the population. In DA, each derived canonical variable is orthogonal (perpendicular) to the previous axis and describes progressively less information in the data set. The relative importance of each canonical variable in describing the multivariate data cluster was assessed by the relative magnitude of the eigenvalues expressed as a proportion of the sum of the eigenvalues.

The discriminant scores were derived from a linear combination of the original variables and represented the new multivariate data. I derived the centroid for each group and assessed distribution in multivariate space using multi-way $95 \%$ confidence intervals.

I used a multivariate analysis of covariance (MANCOVA) to model the influence of aircraft type (military jet, military cargo plane, floatplane or helicopter) and noise $\left(\mathrm{L}_{\text {max }}\right)$ on behaviour of paired harlequin ducks at Fig River. I modelled the influence of noise as a quadratic term because the behavioural response alert was non-linear (Goudie \& Jones 2004). I was especially interested in the interaction term of aircraft and noise as a potential means to assess whether behavioural responses of harlequin ducks were independent of aircraft type.

\section{RESULTS}

\section{Effects of aircraft disturbance on behaviour}

I present data separately for females and males because I knew a priori that there were inherent gender differences in behaviours, particularly the display of greater vigilance by males (Squires 2003; Squires et al. 2006). There were substantial differences in behaviour between undisturbed and aircraft-disturbed female (Wilks' lambda $=0.060, p<0.0001$ ) and male (Wilks' lambda $=0.094, p<0.0001$ ) harlequin ducks at Fig River, Labrador (Table 2). In the presence of aircraft, alert behaviour, inactivity, comfort (preening) and vigilance increased significantly, and out of water behaviour decreased (Fig. 1). I modelled disturbed and undisturbed females and males together using a discriminant analysis in order to highlight differences indicated in the MANOVA (Wilks' lambda $=0.0645, p<0.0001)$.

Harlequin ducks that were exposed to aircraft over-flights exhibited alert behaviour, became inactive and spent less time out of water (canonical variable 1 [CV1]; 73.1\% of the variance). Paired males spent more time vigilant and less time preening than paired females (CV2; 24.3\% of the variance) (Table 3). The CV1 provided maximum discrimination of the disturbed versus undisturbed cohorts, and I interpreted CV2 to be related to within-pair behaviour, particularly the role of increased vigilance by males within synchronized activities of pairs (Squires 2003; Goudie 2004). CV3 explained only $2.3 \%$ of the variance and I interpreted that it did not convey important information (Fig. 2).

Table 2 Univariate ANOVAs (females $F_{60,843}$; males $F_{55,850}$ ) from the MANOVA for paired adult harlequin ducks exhibiting undisturbed and aircraft-disturbed behaviour. ho $=$ behaviour recorded out of water.

\begin{tabular}{lccccc}
\hline \hline Behaviour & \multicolumn{2}{c}{ Female } & & \multicolumn{2}{c}{ Male } \\
\cline { 2 - 3 } \cline { 5 - 6 } & ANOVA & \multicolumn{1}{c}{$p$} & & ANOVA & \multicolumn{1}{c}{$p$} \\
\hline Agonistic & 1.38 & 0.032 & & 1.39 & 0.036 \\
Agonistic (ho) & 1.03 & 0.411 & & 1.59 & 0.005 \\
Court & 0.47 & 0.999 & & 0.47 & 0.999 \\
Feed & 2.13 & $<0.0001$ & & 2.35 & $<0.0001$ \\
Locomotion & 2.59 & $<0.0001$ & & 2.90 & $<0.0001$ \\
Comfort & 9.77 & $<0.0001$ & & 5.71 & $<0.0001$ \\
Comfort (ho) & 2.37 & $<0.0001$ & 2.58 & $<0.0001$ \\
Inactive & 13.64 & $<0.0001$ & 13.52 & $<0.0001$ \\
Inactive (ho) & 2.37 & $<0.0001$ & & 2.12 & $<0.0001$ \\
Vigilant & 9.90 & $<0.0001$ & & 2.15 & $<0.0001$ \\
Vigilant (ho) & 2.15 & $<0.0001$ & & 3.47 & $<0.0001$ \\
Alert & 5.54 & $<0.0001$ & 5.61 & $<0.0001$ \\
Alert (ho) & 0.98 & 0.5234 & & 1.53 & 0.0094 \\
\hline \hline
\end{tabular}



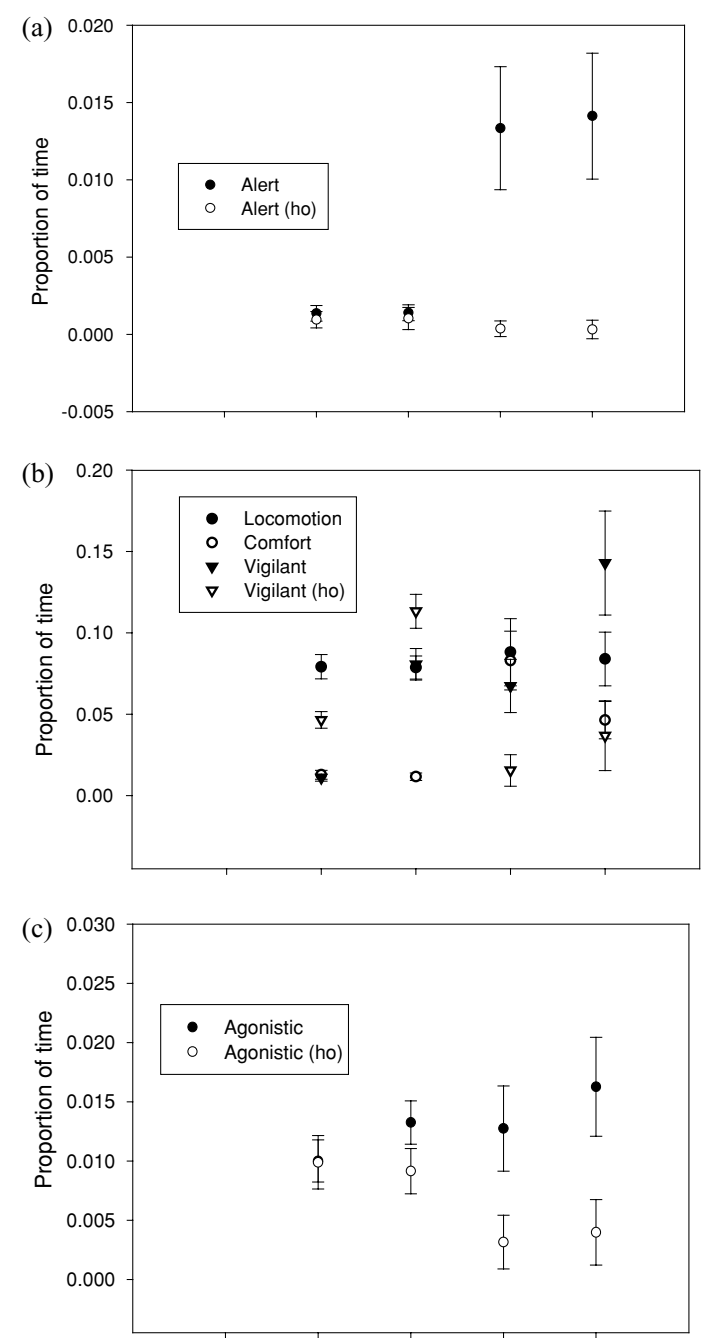

(d)

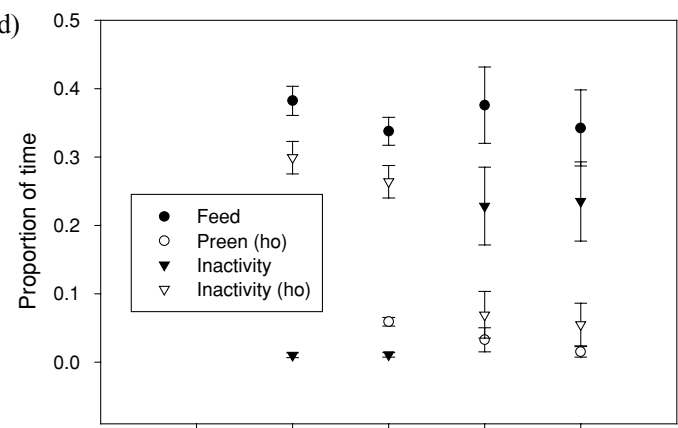

Undisturbed $F$ Undisturbed $M$ Disturbed $F$ Disturbed $M$ GROUP

Figure 1 Mean $( \pm 95 \%$ confidence interval) proportion of time in behaviours for undisturbed and disturbed harlequin ducks at Fig River (Labrador). (a) alert and alert (ho), (b) locomotion, comfort, vigilant and vigilant (ho), (c) agonistic and agonistic (ho) (d) feed, preen (ho), inactivity and inactivity (ho). ho $=$ behaviour recorded out of water, $\mathrm{F}=$ female, $\mathrm{M}=$ male.

\section{Effects of aircraft type on behaviour}

The behavioural effects of aircraft were most pronounced for military jets, although the precision of the magnitude of
Table 3 Correlations between discriminating variables and standardized canonical functions. Bold font indicates largest absolute correlation between each variable and discriminant function. ho $=$ behaviour recorded out of water

\begin{tabular}{lrrr}
\hline \hline Behaviour & \multicolumn{1}{c}{$\boldsymbol{V} \boldsymbol{1}$} & $\boldsymbol{C} \boldsymbol{V} \mathbf{2}$ & \multicolumn{1}{c}{$\boldsymbol{C} \boldsymbol{V} \boldsymbol{1}$} \\
\hline Inactive & $\mathbf{0 . 6 9 6}$ & -0.127 & -0.196 \\
Alert & $\mathbf{0 . 4 6 0}$ & -0.079 & -0.171 \\
Inactive (ho) & $-\mathbf{0 . 2 7 4}$ & -0.049 & 0.014 \\
Vigilant (ho) & 0.260 & $\mathbf{0 . 6 1 8}$ & -0.276 \\
Vigilant & -0.148 & $\mathbf{0 . 5 7 9}$ & 0.310 \\
Comfort (ho) & -0.251 & $-\mathbf{0 . 4 2 5}$ & -0.200 \\
Feed & -0.011 & $-\mathbf{0 . 1 4 5}$ & -0.001 \\
Agonistic & 0.053 & $\mathbf{0 . 1 2 0}$ & -0.055 \\
Comfort & 0.451 & -0.197 & $\mathbf{0 . 7 4 5}$ \\
Locomotion & 0.027 & -0.013 & $\mathbf{0 . 0 3 4}$ \\
\% Variance & 73.1 & 24.3 & 2.6 \\
\hline \hline
\end{tabular}

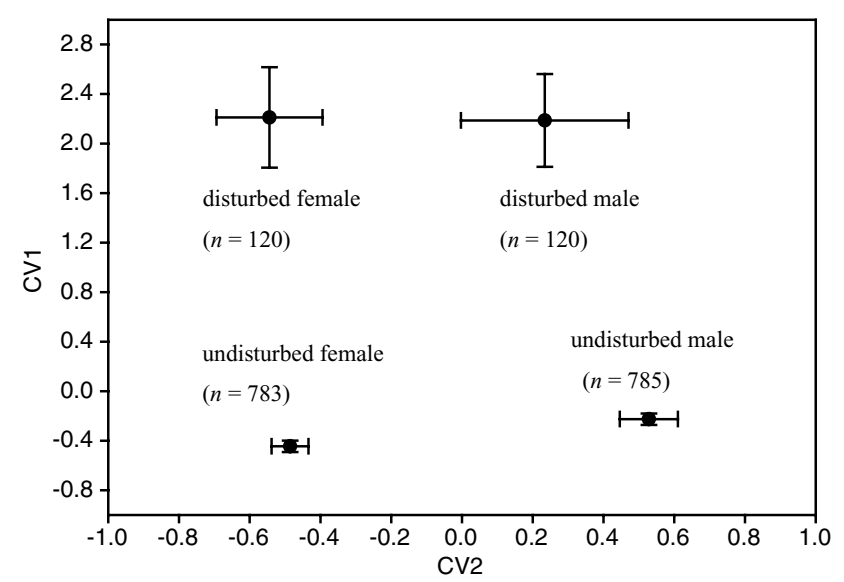

Figure 2 Behaviour of undisturbed and disturbed harlequin ducks at Fig River (Labrador) (centroids with 95\% confidence intervals for discriminant scores). Discriminant scores are derived from linear combinations of original variables that maximize group separation. CV1 represented increasing alert and inactivity, and decreasing inactivity out of the water. CV2 represented increasing vigilance and decreasing preening.

response for helicopter and fixed-wing over-flights was very low; this may be attributable to the small sample size (Fig. 3). There were significant differences in behaviour of harlequin ducks between types of aircraft (MANOVA: females Wilks' lambda $=0.0093, p<0.0001$, males Wilks' lambda $=0.0135$, $p<0.0001)$. These differences were particularly marked for comfort, rest, vigilance and alert behaviours (Table 4).

\section{Effects of aircraft type and noise on behaviour}

Most aircraft noises of high amplitude were generated by military jets but the sample sizes for other types of aircraft were relatively small (Fig. 4). The MANCOVAs that incorporated aircraft type and noise $\left(\mathrm{L}_{\max }\right)$ were significant (females Wilks' lambda $=0.1038, p<0.0001$; males Wilks' lambda $=0.1010$, $p<0.0001)$. However, the interaction terms of aircraft type and noise were significant for important behavioural categories 


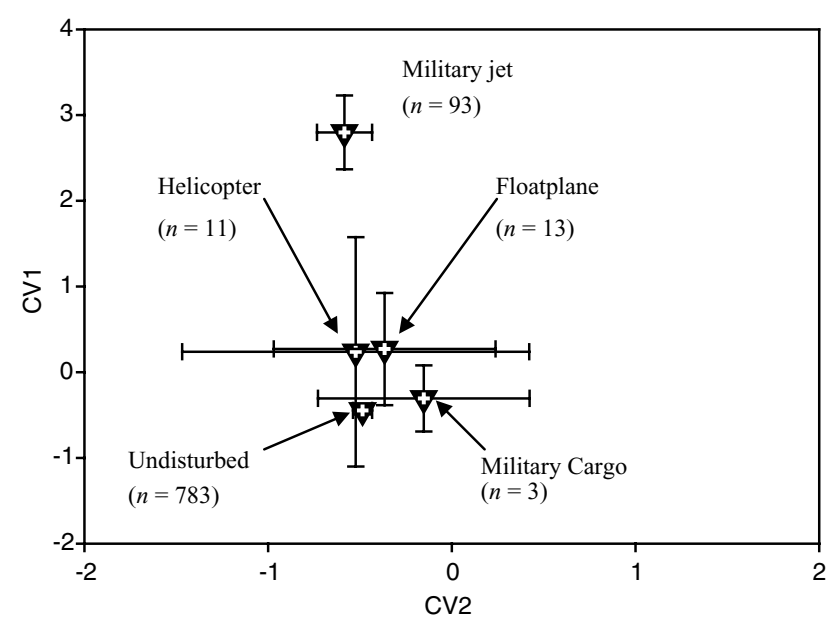

Figure 3 Behaviour of paired harlequin ducks at Fig River (Labrador) in relation to aircraft type (centroids with 95\% confidence intervals for discriminant scores). CV1 represented increasing alert and inactivity, and decreasing inactivity out of the water. CV2 represented increasing vigilance and decreasing preening.

that differed between disturbed and undisturbed groups (Table 4). A curvilinear relationship of behaviours (CV1) with maximum noise level detected during standard 30minute observation periods explained $>40 \%$ of the overall variance in behaviour (females CV1 $=2.915-0.1225 \mathrm{~L}_{\max }+$ $0.0011 \mathrm{~L}_{\max 2}, F_{2,405}=157.50, p<0.00001, R^{2}=0.4375$; males $\mathrm{CV} 1=1.618-0.084 \mathrm{~L}_{\max }+0.0009 \mathrm{~L}_{\max 2}, F_{2,406}=137.99$, $p<0.00001, R^{2}=0.4047$; Fig. 5).

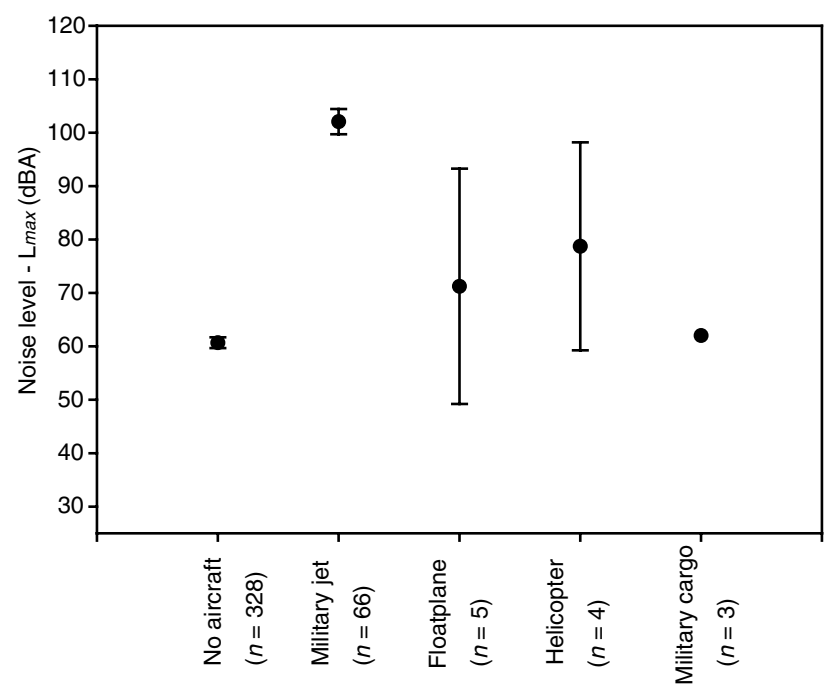

Figure 4 Mean noise levels ( $\mathrm{L}_{\max }$ in dBA with 95\% CI) for four aircraft types measured during behavioural watches of paired harlequin ducks at Fig River (Labrador).

\section{DISCUSSION}

\section{Effects of aircraft disturbance on behaviour}

Harlequin ducks at Fig River, Labrador, responded to low flying aircraft by increasing alert behaviour and becoming inactive or immobile. The alert response to noise generated from low-level military jets increased in a doseresponse manner (Goudie 2004; Goudie \& Jones 2004). The multivariate approach used modelled the covariance among a suite of response behaviours that was not originally detected in the univariate analyses using a before-after-control-impact
Table 4 Univariate ANCOVAs of the MANCOVA for undisturbed and aircraft-disturbed behaviour for paired adult harlequin ducks versus aircraft type and noise. ho $=$ behaviour recorded out of water, ${ }^{*}=$ significant behavioural category in CV1 for discriminating disturbed from undisturbed groups.

\begin{tabular}{llllllc}
\hline \hline Behaviour & $\begin{array}{l}\text { Noise } \\
\left(L_{\text {max }}\right)\end{array}$ & $p$ & $\begin{array}{l}\text { Aircraft } \\
\text { type }\end{array}$ & $p$ & Noise $\times$ type & $p$ \\
\hline Paired females & $F_{1,286}$ & & $F_{32,286}$ & & $F_{32,286}$ & \\
Feed & 0.14 & 0.705 & 0.86 & 0.695 & 0.90 & 0.625 \\
Preen & 0.68 & 0.410 & 1.52 & 0.040 & 1.33 & 0.118 \\
Preen (ho) & 0.001 & 0.946 & 1.95 & 0.0023 & 1.88 & 0.004 \\
Inactive* & 0.04 & 0.840 & 6.72 & $<0.0001$ & 6.87 & $<0.0001$ \\
Inactive (ho) & 0.09 & 0.765 & 0.50 & 0.990 & 0.51 & 0.987 \\
Vigilant & 1.47 & 0.227 & 0.86 & 0.691 & 0.87 & 0.675 \\
Vigilant (ho) & 0.00 & 0.981 & 0.53 & 0.985 & 0.54 & 0.982 \\
Alert* & 3.82 & 0.052 & 1.98 & 0.002 & 1.91 & 0.003 \\
Alert (ho) & 0.01 & 0.939 & 1.72 & 0.012 & 1.39 & 0.086 \\
Paired males & $F_{1,295}$ & & & & $F_{30,295}$ & \\
Feed & 0.03 & 0.859 & 0.82 & 0.741 & 0.85 & 0.694 \\
Preen & 0.12 & 0.725 & 0.203 & 0.002 & 1.83 & 0.006 \\
Preen (ho) & 0.17 & 0.684 & 1.45 & 0.066 & 1.44 & 0.070 \\
Inactive* $_{\text {Inactive (ho) }}^{*}$ & 0.01 & 0.915 & 5.39 & 0.0001 & 5.49 & 0.0001 \\
Vigilant $_{\text {Vigilant (ho) }}$ & 0.08 & 0.783 & 0.51 & 0.986 & 0.53 & 0.980 \\
Alert* & 0.00 & 0.961 & 1.12 & 0.305 & 0.96 & 0.528 \\
Alert (ho) & 0.03 & 0.863 & 1.53 & 0.041 & 1.62 & 0.250 \\
\hline \hline
\end{tabular}


(a)

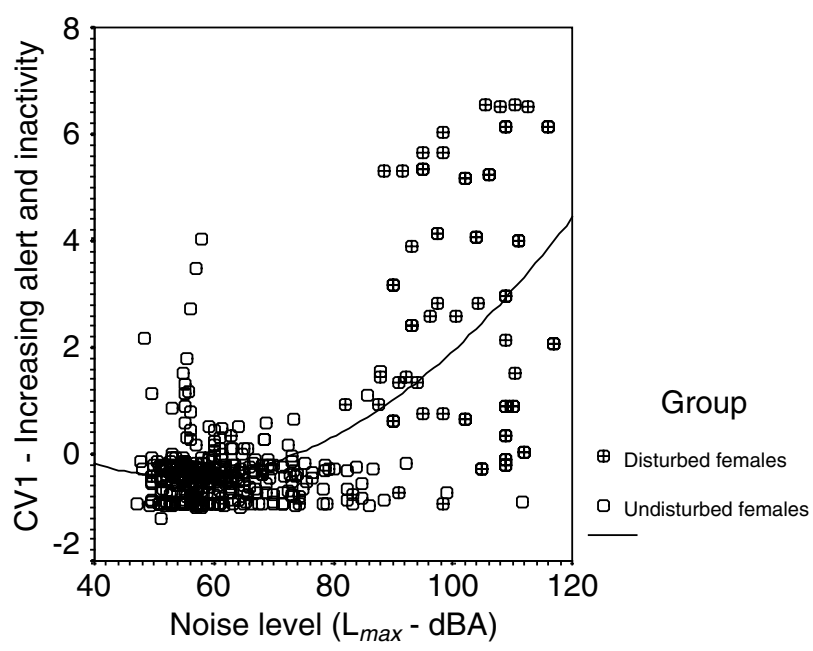

(b)

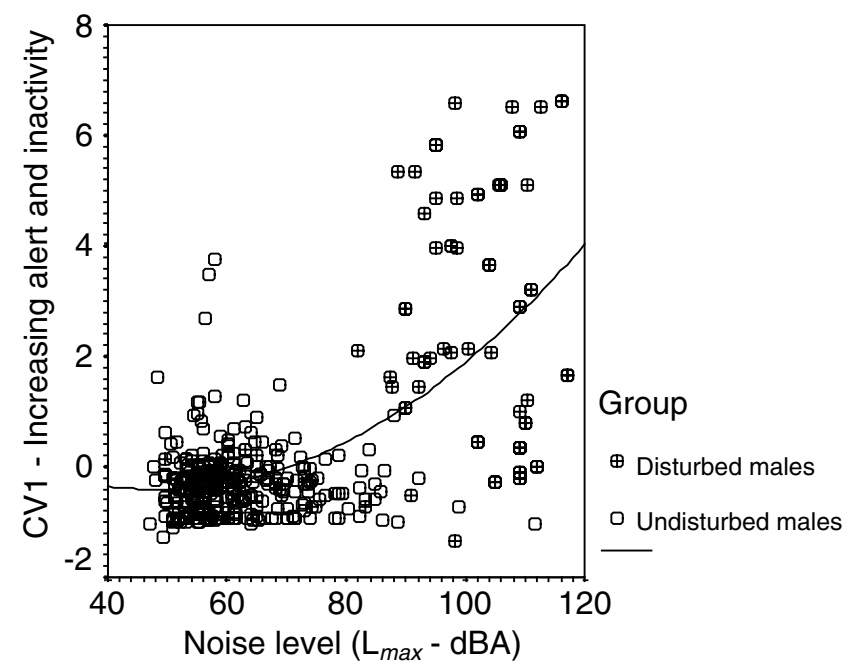

Figure 5 Relationship of canonical variable 1 to maximum noise level $\left(\mathrm{L}_{\max }\right.$ in $\left.\mathrm{dBA}\right)$ detected during standard observation of harlequin ducks at Fig River (Labrador). (a) paired females and (b) paired males.

design. These findings are important because studies of effects of disturbance on behaviour may be biased to detecting overt responses (Trimper et al. 1998). Once animals stop moving or commence feeding or normal locomotion, observers may perceive that the individuals have returned to 'normal' behaviour (Harrington \& Veitch 1991).

Detection of protracted or residual effects may be substantiated through before-during-after analyses (Goudie \& Jones 2004), but are best evidenced through a multivariate statistical design because it models covariance that is otherwise masked in univariate analyses. Harrington and Veitch (1991) noted that 5-10 minutes elapsed before behaviour of caribou returned to pre-disturbance levels, and that it was likely that heart rate remained elevated for several minutes following a jet overpass. Inactivity can be part of the behavioural response to noise disturbance.

\section{Effects of aircraft type and noise on behaviour}

Noise generated from military jet over-flights can be very high in amplitude (for example up to $131 \mathrm{~dB}$; Harrington \& Veitch 1991; Goudie \& Jones 2004). Sound pressure levels under $90 \mathrm{~dB}$ are less aversive to animals (Manci et al. 1988). In general, at Fig River there were stronger behavioural responses by harlequin ducks demonstrated for military jet over-flights than other aircraft (i.e. fixed-wing, helicopter or cargo plane), but my sample sizes for other aircraft were relatively small and I noted that, under certain conditions, responses to the other types of aircraft were relatively large; this accounted for the large demonstrated variance. At Fig River, the noise generated from military jet over-flights was of higher amplitude than other aircraft. The significant interaction term of aircraft type and noise $\left(\mathrm{L}_{\max }\right)$ in the GLM of effects on behaviour indicated that it was not possible to separate effects of aircraft type from generated noise based on my relatively low samples of aircrafts other than military jets.

Noise may be the primary stressor in aircraft disturbance (Brown 1990, 2001b; Harrington \& Veitch 1991; Ward et al. 2001) and $43.1 \%$ of the variance in the behaviour of paired harlequin ducks that were disturbed at Fig River was explained by noise. Causal association can most convincingly be established by demonstrating increase in response with increase in the level of exposure (Bowles et al. 1991; Bowles 1994). My findings could be applied to reduce effects of military jet noise on harlequin ducks in the Military Training Area of Labrador (Goudie 2004) by avoiding watersheds or reducing noise exposure by altitude limitations (Goudie \& Jones 2004). Overall, these results support the need for studies directed towards population consequences of military aircraft disturbance.

At Fig River, most over-flights by military jets that coincided with behavioural observations of harlequin ducks were less than $100 \mathrm{~m}$ above ground level. It is possible that at such a low altitude the high amplitude noise masked any effect of aircraft type. Behavioural responses of animals may vary by aircraft type beyond some threshold of distance (Harrington \& Veitch 1991). For example, Grubb and Bowerman (1997) argued that at distances to aircraft of less than $166 \mathrm{~m}$ there were no effects of aircraft type on behaviour of bald eagles (Haliaetus leucocephalus), whereas stronger responses to helicopters than to military jets and light planes were documented beyond this distance. Ward et al. (2001) demonstrated that noise generated from helicopters can increase with distance from the animals, and evidence supports that noise is the primary stressor in aircraft over-flights (Brown 2001b). Longer responses to helicopters than military jets may be a consequence of slower air speeds and greater visual detection. Additionally, helicopters actively pursue caribou (and closely approach eyries in raptor research; see Trimper et al. 1998) especially 
for wildlife research, and animals may associate this aircraft with the threat posed by predators.

\section{CONCLUSIONS}

Harlequin ducks responded to high amplitude noise generated by low-flying military jets. Responses were overt, including alert and startle behaviours, but also included less detectable effects, such as inactivity. The modelling of a suite of behaviours using multivariate techniques integrated the covariance structure and provided a holistic way to assess all behavioural aspects of the more immediate effects of aircraft over-flights. I conclude that conventional univariate approaches to studies of behavioural responses to disturbance may be biased by the a priori selection of response variables, because animals may not perform directly observable responses. A group of behaviours may be interrelated and engaged in the actual response, and this is best modelled through multivariate statistical analyses. The resulting canonical variables are linear combinations of the original variables and provide a more robust means to assess the relationship of behavioural response to noise dose.

\section{ACKNOWLEDGEMENTS}

For fieldwork, I am grateful to the numerous field assistants and many contacts who helped the success of this large research project. I especially thank Simon Andrew, Ben Andrew, Guy Andrew, Eric Andrew and their families. The continued support for this project from the Institute for Environmental Monitoring and Research (IEMR) was possible because of the persistence of Tom Jung, Research Director, and the Innu Nation. Colin Jones, Keith Oram and Bruce MacTavish provided substantial multi-year field assistance. For project, logistic and organizational help I thank Department of National Defence and staff of the IEMR, and the Northern Research Institute of Memorial University of Newfoundland and Labrador (MUN). Thanks for the hard work of the administrative and purchase-supply staff of the Department of Biology, MUN. For statistical advice and study design, I am grateful to Dr Anne Bowles, Dr Stephen Insley, Tom Jung, Dr Greg Robertson and Dr David Schneider. Geoff Goodyear, Jim Hudson, Jim Burton and Rick Dawe provided major aircraft support. The IEMR, the Canadian Wildlife Service, the Atlantic Cooperative Wildlife Ecology Research Network, the Endangered Species Recovery Fund of World Wildlife Fund Canada, the Dean of Science of MUN and the Northern Scientific Training Program of the Department of Indian and Northern Affairs (Canada) funded this work.

\section{References}

Altmann, J. (1974) Observational study of behaviour: sampling methods. Behaviour 49: 227-267.
Bowles, A.E. (1994) Responses of wildlife to noise. In: Wildlife and Recreationists: Coexistence Through Management and Research, ed. R.L. Knight \& K.J. Gutswiller, pp. 154-221. Washington, DC, USA: Island Press.

Bowles, A.E., Tabachnick, B. \& Fidell, S. (1991) Review of the effects of aircraft overflights on wildlife: Volume II of III: Technical Report. BBN Systems and Technologies, Canoga Park, CA, Canada.

Brown, A.L. (1990) Measuring the effect of aircraft noise on sea birds. Environment International 16: 587-592.

Brown, A.L. (2001a) Overview of research on the effects of noise on wildlife. Terra Borealis 2: 10-14.

Brown, A.L. (2001b) The response of sea birds to simulated acoustic and visual aircraft stimuli. Terra Borealis 2: 56-59.

DND (1994) EIS: military flight training - an environmental impact statement on military flying activities in Labrador and Quebec. Unpublished Environmental Assessment, Project Management Office Goose Bay, National Defence Headquarters, Ottawa, Canada.

Goudie, R.I. (2004) The effects of aircraft disturbance on behaviour of harlequin ducks (Histrionicus histrionicus). Ph.D. thesis, Memorial University of Newfoundland, St John's, Newfoundland, Canada, A1B 3X9.

Goudie, R.I. \& Jones, I.L. (2004) Dose-response relationships of harlequin duck behaviour to noise from low-level military jet overflights in central Labrador. Environmental Conservation 31(4): 110 .

Goudie, R.I., Brault, S., Conant, B., Kondratyev, A.V., Petersen, M.R. \& Vermeer, K. (1994) The status of sea ducks in north Pacific Rim: toward their conservation and management. Transactions of the North American Wildlife and Natural Resources Conference 59: 27-49.

Grubb, T.G. \& Bowerman, W.W. (1997) Variations in breeding bald eagle response to jets, light planes and helicopters. Fournal of Raptor Research 31: 213-222.

Harrington, F.H. \& Veitch, A.M. (1991) Short-term impacts of low-level jet fighter training on caribou in Labrador. Arctic 44: 318-327.

Korn, J.H. \& Moyer, K.E. (1966) Habituation of the startle response and of heart rate in the rat. Canadian fournal of Psychology 20(2): 183-190.

Larson Davis Laboratories (1997) Model 820 Sound Level Meter user manual. Unpublished document, Larson Davis Inc., Utah, USA.

Martin, P. \& Bateson, P. (1986) Measuring Behaviour: an Introductory Guide. New York, USA: Cambridge University Press.

McGarigal, K., Cushman, S. \& Stafford, S. (2000) Multivariate Statistics for Wildlife and Ecology Research. New York, NY, USA: Springer-Verlag: 283 pp.

Pater, L. (2001) Defining auditory thresholds for animal species. Terra Borealis 2: 22-25.

Pigeon, M.A. (2001) Managing low level jet aircraft noise. Terra Borealis 2: 64-68.

Ryals, B.M., Dooling, R.J., Westbrook, E., Dent, M.L., MacKenzie, A. \& Larsen, O.N. (1999) Avian differences in susceptibility to noise exposure. Hearing Research 131: 71-88.

SAS Institute Inc. (1999) SAS system for windows. Cary, NC, USA. Squires, K.A. (2003) Pre-incubation behaviour of Harlequin ducks (Histrionicus histrionicus) in Labrador: testing the function of male vigilance and aggression. Masters thesis, Faculty of Forestry, 
University of British Columbia, Vancouver, BC, Canada: $53 \mathrm{pp}$.

Squires, K.A., Martin, K. \& Goudie, R.I. (2006) Vigilance behavior in harlequin ducks (Histrionicus histrionicus) during the preincubation period in Labrador: are males vigilant for self or social partner. Auk (in press).
Trimper, P.G., Standen, N.M., Lye, L.M., Lemon, L., Chubbs, T.E. \& Humphries, G.W. (1998) Effects of low-level jet aircraft noise on the behaviour of nesting osprey. Fournal of Applied Ecology 35: 122-130.

Ward, D.H., Stehn, R.A. \& Derksen, D.V. (2001) Response of geese to aircraft disturbance. Terra Borealis 2: 52-55. 